\title{
Siting and sizing of wind farms taking into account stochastic nature of generation
}

\author{
Vladislav Shakirov ${ }^{1, *}$, Victor Kurbatsky ${ }^{2}$, Nikita Tomin $^{2}$ and Huseyngulu Guliyev ${ }^{3}$ \\ ${ }^{1}$ Melentiev Energy Systems Institute, Department of Complex and Regional Problems in Energy, 130 Lermontov str., Irkutsk, Russia \\ ${ }^{2}$ Melentiev Energy Systems Institute, Department of Electric Power Systems, 130 Lermontov str., Irkutsk, Russia \\ ${ }^{3}$ Azerbaijan Scientific-Research and Designed-Prospecting Power Engineering Institute, Hasanbey Zardabi av. 94, Baku, Azerbaijan
}

\begin{abstract}
The article deals with the problem of the negative impact of wind farms stochastic generation on power grid. One of the ways to reduce the stochasticity of the wind farms generation is their geographically distributed siting. A technique for sizing and distributed siting of wind farms from the standpoint of the influence on the variability of the total generated power is proposed. Modeling of wind power generation with hourly detailing is carried out using the developed Wind-MCA software based on data from archives of long-term observations of ground-based weather stations. The optimal distribution of wind turbines in potential locations is based on a genetic algorithm. The objective function is the coefficient of variation of the power generated by all wind farms in the sites under consideration, depending on the number of wind turbines in their composition. The genetic algorithm is implemented using the built-in MATLAB function. The proposed technique is applied to assess the capacity options and sites for wind farms in the Zabaykalsky Krai. The solution providing the minimum value of the coefficient of variation of the wind farms generated power and high value of the wind farms capacity utilization factor has been obtained.
\end{abstract}

\section{Introduction}

According to the Energy Strategy of Russia for the period up to 2035, implementation of the spatial priorities of the state energy policy assumes increasing stability and reliability of energy supply to macroregions with maximum, cost-effective use of local and renewable energy sources.

Over the period from 2016 to 2020 , the installed capacity of grid wind farms (WF) in Russia increased from 10.9 to $184 \mathrm{MW}$ due to investments attracted under power supply agreements. In the period until 2024 , it is expected to commission WF with a total capacity of 3.4 GW.

When designing WF of high power, it is necessary to assess their impact on power system. The main negative factor is the wind speed variability, which leads to fluctuations in the wind turbines (WT) power output. When the share of WF in power generation is more than $15-20 \%$, there is a danger of influencing the power system transient stability [1-4]. To cover possible sudden power fluctuations from WF, an increase in the operating reserve of the power system is required [5]. The required additional amount of reserve at traditional power plants is commensurate with the WF capacity.

WF with the capacity of several tens or hundreds of MW connected to power grid at one point has a greater influence on the power balance of the system than a group of WF with the same total capacity distributed over a large territory. This is due to the fact that at any given time the wind regime on the vast territory is different.

The influence of the distributed location of WF on power fluctuations for the regions of the USA and Europe is analyzed in [6-9]. The work [10] presents the results of a study on the influence of the distributed location of WF on operating reserve requirements.

The article proposes a technique for sizing and distributed siting of WF from the standpoint of the influence on the variability of the total generated power.

\section{Methodology for sizing distributed siting of wind farms}

Figure 1 shows the main stages of the WF capacity and distributed location choice according to the criterion of minimizing the generated power variability.

\begin{tabular}{l}
\hline 1. Determination of promising areas for wind farms \\
$\begin{array}{l}\text { 2. Estimation of hourly electricity generation by one wind } \\
\text { turbine for the study period in each area }\end{array}$ \\
$\begin{array}{l}\text { 3. Assessment of variability indicators of power generation } \\
\text { by wind turbine in each area }\end{array}$ \\
$\begin{array}{l}\text { 4. Determination of the optimal number of wind turbines in } \\
\text { areas using genetic algorithm }\end{array}$ \\
\hline
\end{tabular}

Fig. 1. Methodology for sizing and distributed siting of wind farms

\footnotetext{
* Corresponding author: mynovember $@$ mail.ru
} 
At Stage 1, the territory is analyzed and possible areas of WF siting are identified. At the same stage the estimation of the average annual wind speed is also carried out to exclude from consideration areas with obviously low wind energy potential. So, taking into account the WT cut-in speed at the level of $3-4 \mathrm{~m} / \mathrm{s}$, it is possible to exclude areas with such a wind speed, taking into account its adjustment for the rotor height:

$$
V_{i}=V_{\text {meas }}\left(\frac{h_{i}}{h_{\text {meas }}}\right)^{m} \text {, }
$$

where $V_{i}$ is the wind speed at the height of the WT rotor $h_{i}, \mathrm{~m} / \mathrm{s} ; V_{\text {meas }}$ is the wind speed at the height of the weather station vane $h_{\text {meas }}, \mathrm{m} / \mathrm{s} ; m$ is the power coefficient depending on the wind speed and the roughness of the underlying surface.

At the second stage the estimation of hourly electricity generation by one WT for the period for which data on wind speed are available for all considered areas is carried out. For this purpose, it is most efficient to use data from observations of groundbased weather stations [11-13].

Using the Wind-MCA computer program [13], wind speed data are imported from the resource https://rp5.ru, which provides archival statistically raw data of longterm measurements of ground-based weather stations in Russia (Fig. 2). Since measurements at weather stations are carried out 4-8 times a day, the intermediate values of the wind speed are determined by the interpolation method.

The calculation of WT electricity generation for the considered period is carried out by the expression:

$$
W=\sum_{i=1}^{n} P\left(V_{i}\right),
$$

where $P\left(V_{i}\right)$ is the WT electric power output corresponding to the wind speed $V_{i}$ in the $i$-th hour, MW; $n$ is the number of hours in a year.

The calculation of $P\left(V_{i}\right)$ is performed in the WindMCA according to the WT power curve (Fig. 3).

At stage 3, the WT power generation variability in each area is estimated using the coefficient of variation and the power duration curve (Fig. 4). The power duration curve shows the number of hours during which the WF operated with a power not less than the considered one.

For example, in Fig. 4 the curve shows that the WF power was at least $10 \%$ of the rated value for 4883 hours. The lack of the WF power generation is estimated at 1879 hours. The maximum WF power output was provided for 225 hours.

In accordance with Fig. 1, at the fourth stage, the optimization of the distribution of WT in the areas is performed using a genetic algorithm. The objective function $F(m)$ is minimized:

$$
\begin{aligned}
& F\left(m_{1}, m_{2}, \ldots m_{q}\right)=\frac{n}{\sum_{i=1}^{n} \sum_{j=1}^{q} m_{j} P\left(V_{j i}\right)} . \\
& \sqrt{\frac{\sum_{i=1}^{n}\left(\sum_{j=1}^{q} m_{j} P\left(V_{j i}\right)-\frac{1}{n} \sum_{k=1}^{n} \sum_{j=1}^{q} m_{j} P\left(V_{j k}\right)\right)^{2}}{n}}
\end{aligned}
$$

where $m_{j}$ is the number of WT in the $j$-th area; $q$ is the number of areas; $P\left(V_{j i}\right)-\mathrm{WT}$ power output in the $i$-th hour in the $j$-th area, MW.

Expression (3) is the coefficient of variation of the power generated by all WF in the areas under consideration, depending on the number of WT in their composition.

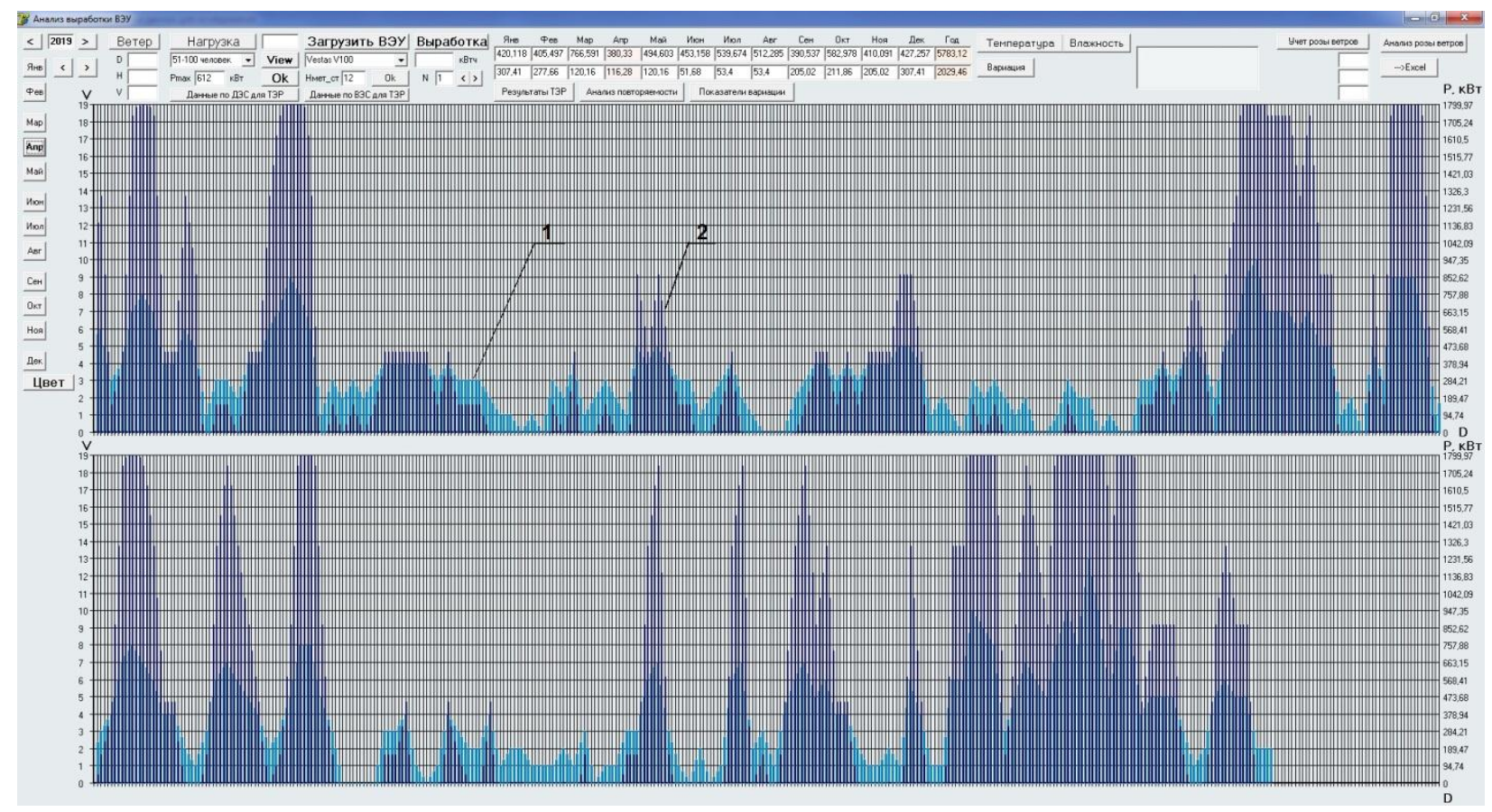

Fig. 2. The working screen of the Wind-MCA software: 1 - wind speed, $\mathrm{m} / \mathrm{s} ; 2$ - WT power generation during a month, kW 


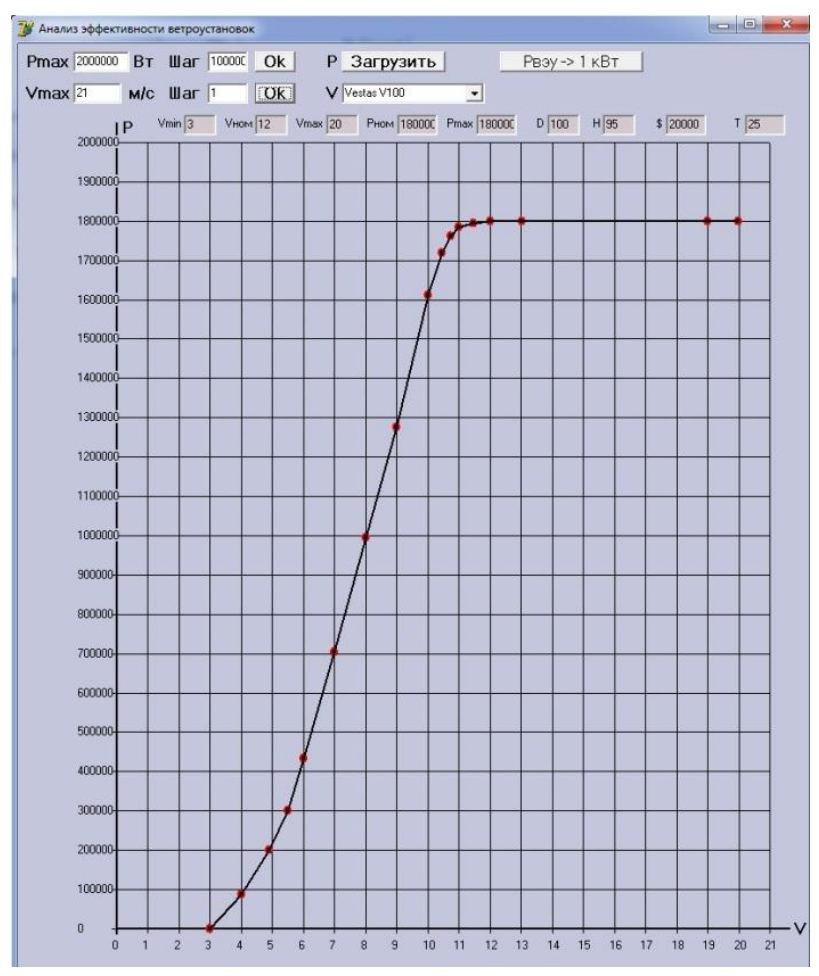

Fig. 3. The working screen of the Wind-MCA software. Power curve of the wind turbine Vestas V100-1,8 MW

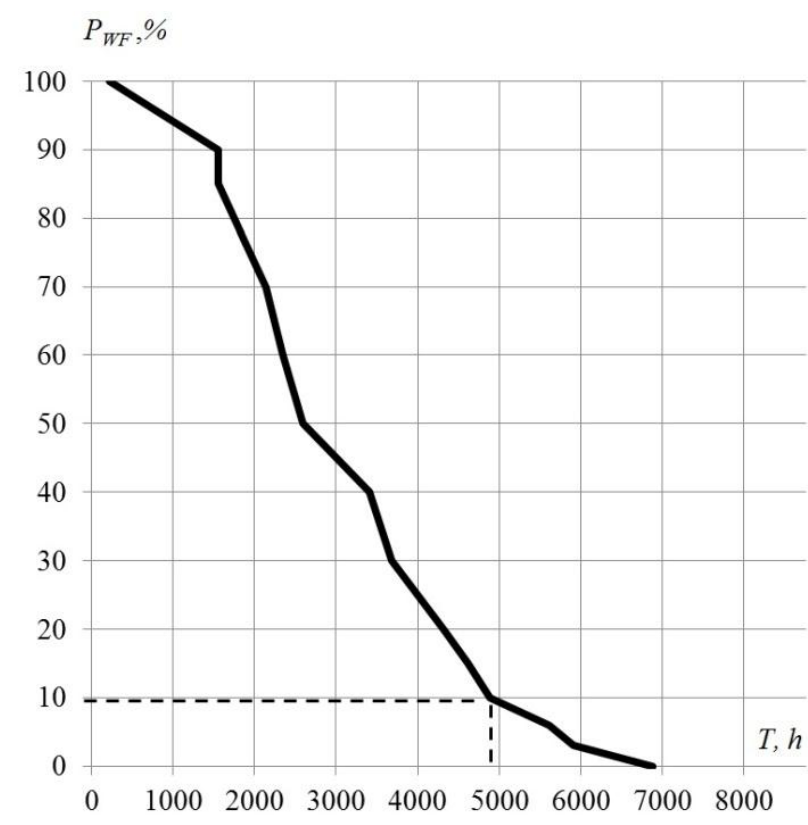

Fig. 4. Power duration curve.

The genetic algorithm is implemented using the builtin MATLAB function. The initial information for optimization on the WT power generation, $P\left(V_{j i}\right)$, is imported from the Wind-MCA.

As a result of optimization, the number of WT in the composition of WF of each considered area is determined in such a way that the minimum of the objective function (3) is provided.

In the final comparison of WF siting options, power duration curves are used.

\section{Application of the methodology for sizing and distributed siting of wind farms}

The proposed method is applied to assess options for WF siting in the Zabaykalsky Krai. This region is characterized as not very promising for the use of wind energy, however, some areas have a relatively high wind potential, for example, the areas of the Aksha, Ulety weather stations. To increase the efficiency of WT in conditions of low wind speed, it is advisable to consider a WT hub height of more than $50 \mathrm{~m}$ [14].

In accordance with the first stage of the methodology (Fig. 1), an assessment of the average annual wind speed was carried out for certain areas with a high density of wind energy potential [14], which have sites for placement and the power grid infrastructure for connecting WF.

Table 1 shows the characteristics of the wind energy potential of the areas, obtained from the analysis of wind speed for the period 2017-2019. An estimate is given of the average wind speed at the height of the WT rotor, the amount of electricity generated by the WT, the capacity utilization factor and the coefficient of variation of the WT power output. The calculation was carried out for a line of WT models manufactured by Vestas, which localized the production of the main elements - blades in Ulyanovsk and gondolas in Dzerzhinsk. The obtained estimates of the capacity utilization factor and the coefficient of variation of the WT power have minor differences for the models. Therefore, the results are given for the model with the lowest unit power -1.8 MW Vestas V100, with a hub height of $95 \mathrm{~m}$.

Based on the estimates of the capacity utilization factor and the coefficient of variation of the WT power output, the most promising areas for WF siting are located near the settlements of Shilka and Ulety. The territory near Sretensk was excluded from the analysis due to low average annual wind speed.

Fig. 5 presents a situational plan with the areas of potential WF location, as well as part of power grid, which shows the connection between the areas through power lines with a voltage of 110 and $220 \mathrm{kV}$.

Fig. 6 shows the MATLAB working screen with the result of optimization of the distributed siting of fifty WT in the targeted areas using a genetic algorithm.

Table 2 shows the results of various options for the WF distributed siting in five regions. The largest number of WT, in accordance with the obtained optimal solution, should be installed in the Uletovsky and Shilkinsky regions, characterized by the smallest coefficient of variation (Table 1). With this solution, the coefficient of variation of WF power output is reduced relative to the values in case of concentrated siting. It also provides a high capacity utilization factor value. Additionally, Table 2 shows estimates of the even WT distribution in five areas, as well as in the three most promising areas. The results of evaluating these solutions show that they are less effective from the standpoint of capacity utilization factor and the coefficient of variation of the WF power output. 
Table 1. Wind potential assessment of selected for study areas of the Zabaikalsky Krai

\begin{tabular}{|c|c|c|c|c|c|}
\hline \multirow{2}{*}{$\begin{array}{c}\text { Weather station } \\
\text { (locality) }\end{array}$} & \multicolumn{2}{|c|}{$\begin{array}{c}\text { Average annual wind } \\
\text { speed at altitude, } \mathbf{~} / \mathbf{s}\end{array}$} & $\begin{array}{c}\text { Average annual } \\
\text { electricity generation } \\
\text { by wind turbine, } \\
\mathbf{M W} \cdot \mathbf{h}\end{array}$ & $\begin{array}{c}\text { Capacity utilization } \\
\text { factor, \% }\end{array}$ & $\begin{array}{c}\text { Coefficient of variation } \\
\text { of the WT power output }\end{array}$ \\
\cline { 2 - 6 } & $\mathbf{1 0 ~ \mathbf { ~ }}$ & $\mathbf{9 5} \mathbf{~ m}$ & 2503 & 15.87 & 1.68 \\
\hline Aginskoe & 2.73 & 4.28 & 2423.6 & 15.37 & 1.74 \\
\hline Aksha & 2.66 & 4.17 & 2832.5 & 17.96 & 1.63 \\
\hline Borzya & 2.89 & 4.53 & 3455.2 & 21.91 & 1.38 \\
\hline Shilka & 3.25 & 5.10 & 3012.7 & 19.11 & 1.45 \\
\hline Ulety & 2.82 & 4.42 & 1642.5 & 10.42 & 2.01 \\
\hline
\end{tabular}

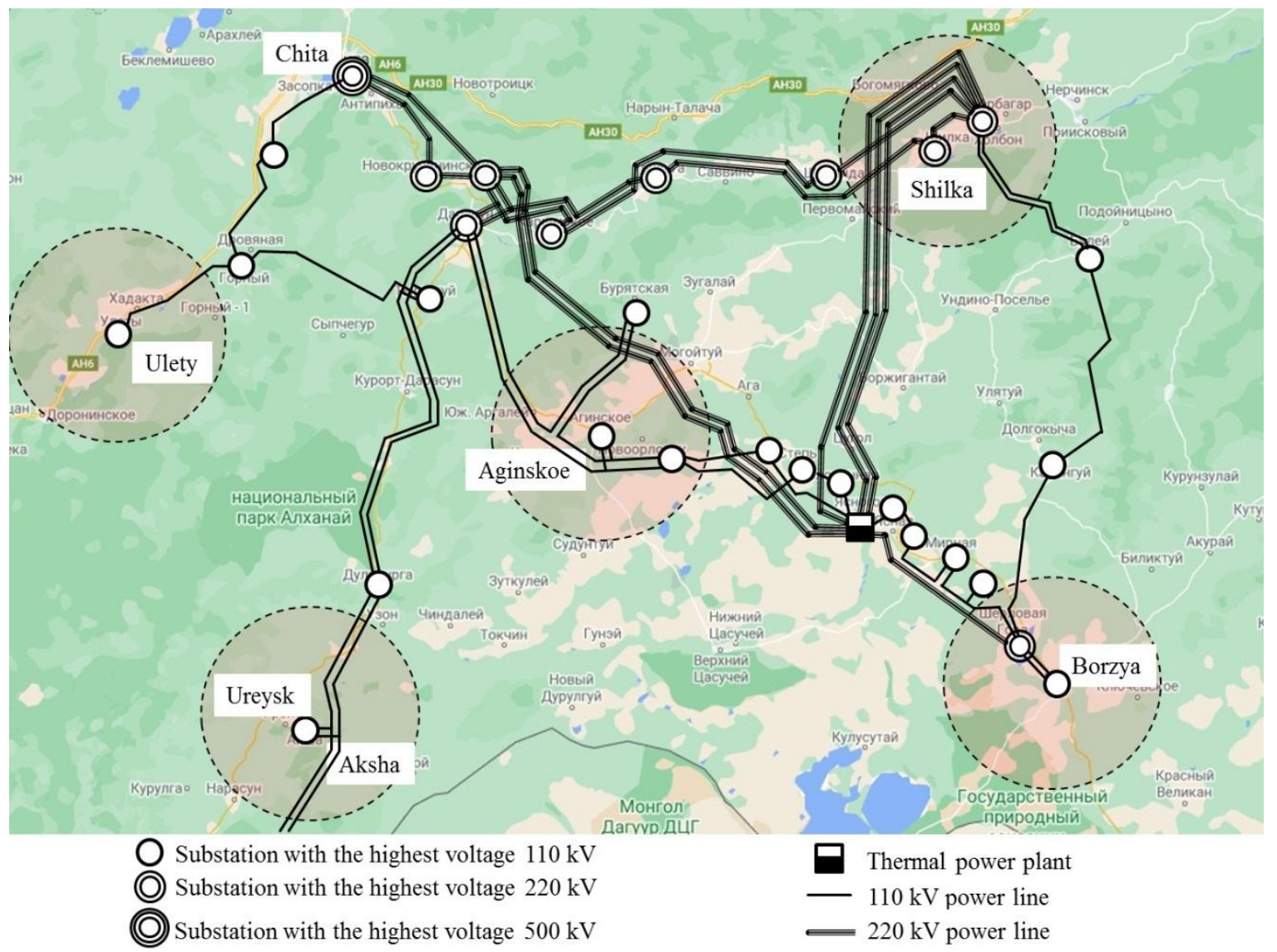

Fig. 5. Situational plan with the areas of potential WF location

Figure 7 shows power duration curves obtained from the wind speed data for 2019. Table 3 compares the curves.

With the distributed WF siting, the duration of the period with the maximum output of all WT decreases, however, the duration of low power generation significantly increases. Thus, the period with the absence of WF production decreased from 2-3.5 thousand hours to 731 hours. The power duration curve for the distributed WF siting is smoothed and flatter, which indicates the possibility of more accurate forecasting of WF power generation. 


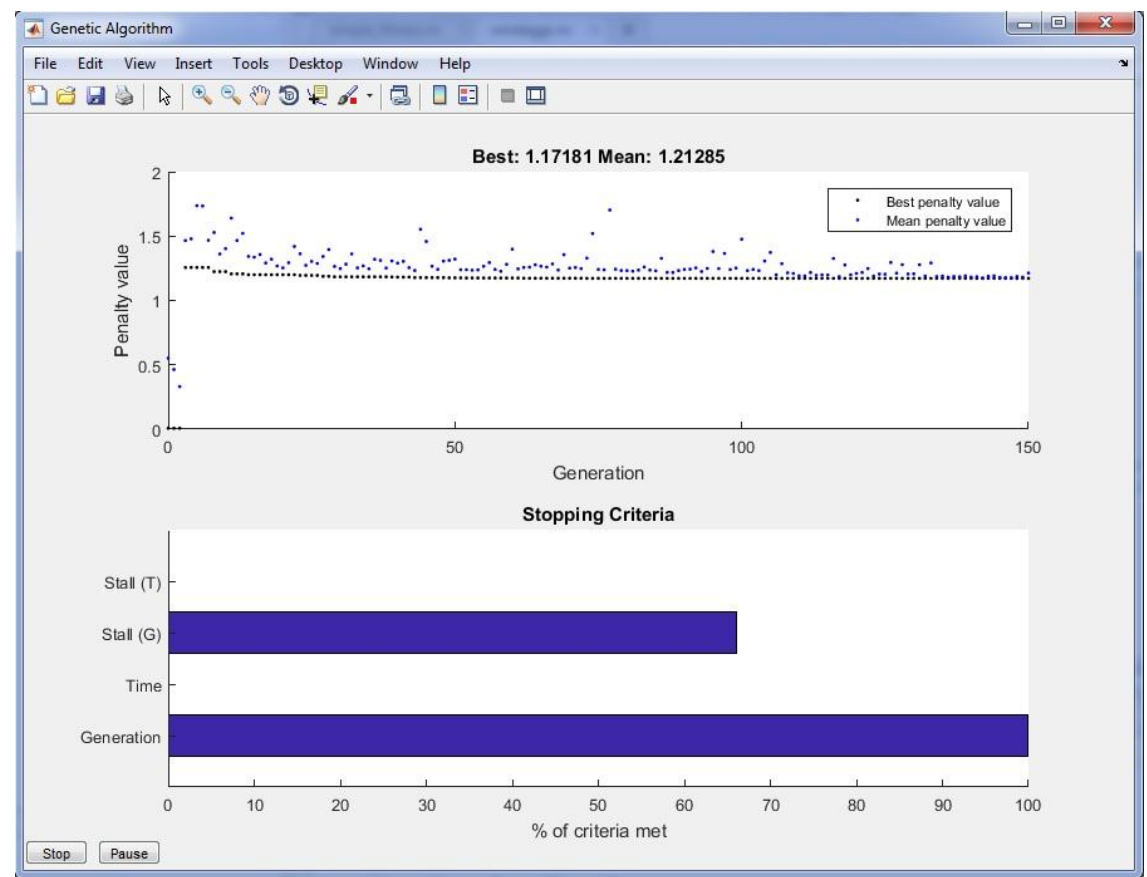

Fig. 6. MATLAB working screen. Optimization result by the genetic algorithm.

Table 2. Results of optimization of wind farms distributed siting

\begin{tabular}{|c|c|c|c|c|c|c|}
\hline \multicolumn{5}{|c|}{ Distributed siting of wind turbines in regions } & \multirow{2}{*}{$\begin{array}{c}\text { Capacity utilization } \\
\text { factor, } \%\end{array}$} & \multirow{2}{*}{$\begin{array}{c}\text { Coefficient of variation } \\
\text { of the WF power } \\
\text { output }\end{array}$} \\
\hline Aginsky & Akshinsky & Borzinsky & Shilkinsky & Uletovsky & & \\
\hline 0 & 0 & 9 & 20 & 21 & 20.02 & 1.17 \\
\hline 10 & 10 & 10 & 10 & 10 & 18.05 & 1.25 \\
\hline 0 & 0 & 17 & 17 & 17 & 19.66 & 1.19 \\
\hline
\end{tabular}

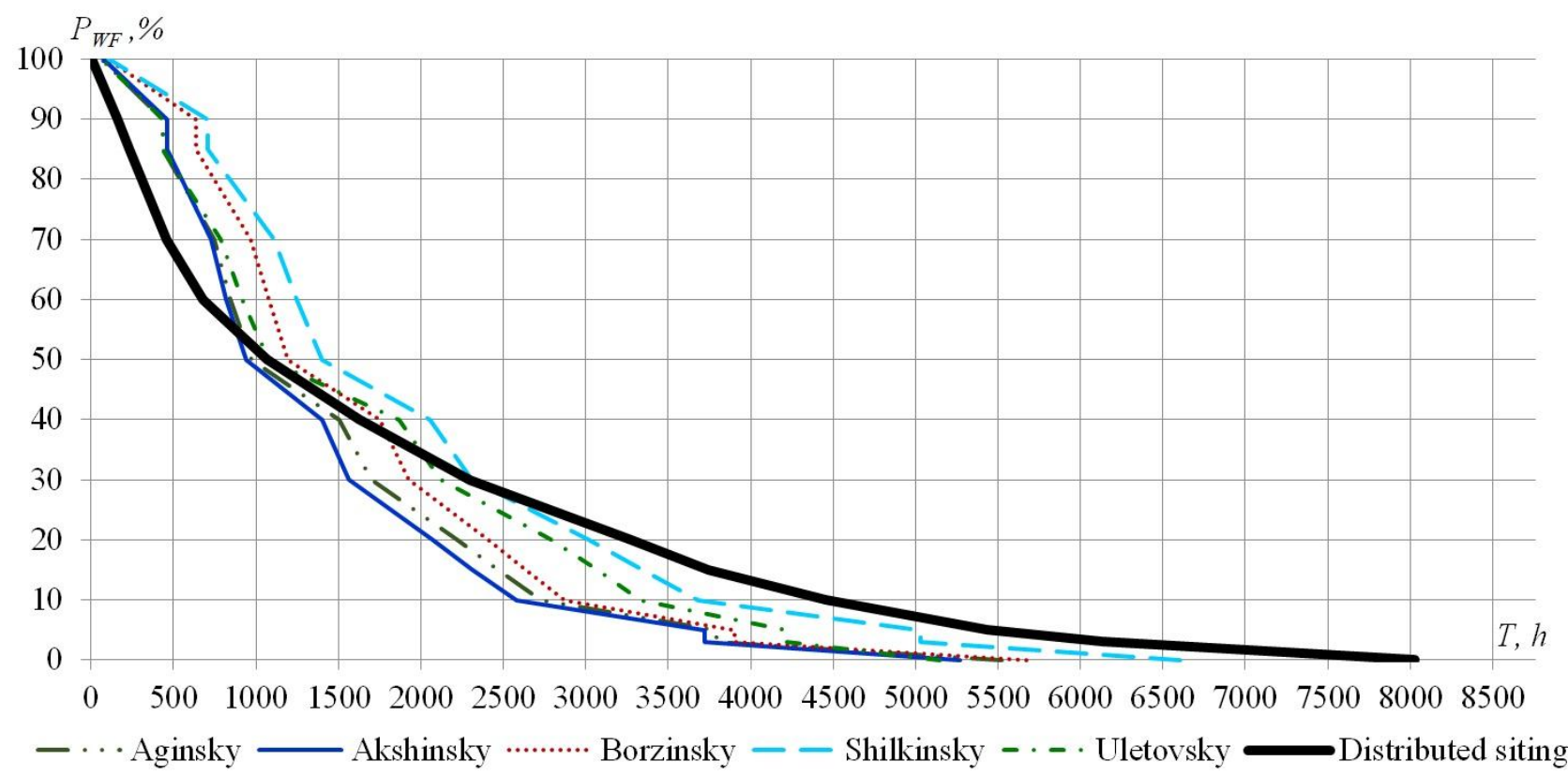

Fig. 7. Power duration curves with concentrated and distributed WF siting 
Table 3. The duration of WF power generation depending on siting options

\begin{tabular}{|c|c|c|c|c|c|}
\hline \multirow{2}{*}{$\begin{array}{c}\text { Wind farm } \\
\text { location } \\
\text { area }\end{array}$} & \multicolumn{2}{|c|}{$\begin{array}{c}\text { The duration of the period } \\
\text { with the total power } \\
\text { generation not less than, }\end{array}$} & $\begin{array}{c}\text { con } \\
\text { Duration of } \\
\text { the period } \\
\text { with no power } \\
\text { generation, h }\end{array}$ \\
\cline { 2 - 6 } & $\mathbf{1 0 0 \%}$ & $\mathbf{8 5 \%}$ & $\mathbf{1 0 \%}$ & $\mathbf{5 \%}$ & 3239 \\
\hline Aginsky & 63 & 433 & 2729 & 3793 & 3492 \\
\hline Akshinsky & 76 & 461 & 2580 & 3721 & 3089 \\
\hline Borzinsky & 97 & 638 & 2875 & 3901 & 2158 \\
\hline Shilkinsky & 107 & 708 & 3683 & 5030 & 3611 \\
\hline Uletovsky & 62 & 433 & 3331 & 4221 & 731 \\
\hline Distributed & 2 & 229 & 4456 & 5433 & \\
\hline siting & & & &
\end{tabular}

With an increase in the number of WF connected to various points of power grid, a certain guaranteed level of power generation can be obtained, which, ultimately, will reduce the required amount of the operating reserve of generating capacities in the electric power system.

\section{Conclusions}

1. In the period until 2024, Russia is expected to commission WF with a total capacity of up to $3.4 \mathrm{GW}$. With a significant WF share in covering the electric power system load, the stochastic nature of generation can affect the transient stability of the system. To cover possible sudden fluctuations in WF power, an increase in the operating reserve of the electric power system is required by an amount commensurate with the WF capacity. In order to reduce power fluctuations, it is advisable to have a distributed WF location.

2. A technique for optimal siting and sizing of WF based on a genetic algorithm using data from long-term observations of weather stations is proposed. The coefficient of variation of the generated power by the WF group is used as an objective function.

3. The analysis of options for the WF siting and sizing in the Zabaykalsky Krai has been carried out. The obtained solution provides the minimum value of the coefficient of variation of the WF power output and a high value of the capacity utilization factor.

4. Analysis of the power duration curves shows a significant increase in the number of WF operation hours per year with their distributed location.

The research was carried out under State Assignment, Project III.17.6.1 (reg. № AAAA-A17-117030310445-9) and III.17.4.2 (reg. № AAAA-A17-117030310438-1) of the Fundamental Research of Siberian Branch of the Russian Academy of Sciences

\section{References}

1. J.O.G. Tande, Grid Integration of Wind Farms. Wind Energ., 6, pp. 281-295 (2003).

2. S. Xia, Q. Zhang, S. Hussain, B. Hong, W. Zou, Impacts of Integration of Wind Farms on Power System Transient Stability. Appl.Sci.,8,1289.(2018).

3. A.P. Sohn, M.B.d.C. Salles, L.F.C. Alberto, Transient Stability of Power Systems Under High Penetrations of Wind Power Generation. Journal of Control, Automation and Electrical Systems, 30, pp. 1116-1125. (2019).

4. O. Benzohra, S.S. Echcharqaouy, F. Fraija, D. Saifaoui. Integrating Wind Energy into the Power Grid: Impact and Solutions, Materials Today: Proceedings, 30, Part 4, pp. 987-992. (2020).

5. C. Rahmann, A. Heinemann, R. Torres, Quantifying operating reserves with wind power: towards probabilistic-dynamic approaches. IET Generation, Transmission \& Distribution, 10(2):366. (2016).

6. S.M. Fisher, J.T. Schoof, C.L. Lant, M.D. Therrell, The effects of geographical distribution on the reliability of wind energy. Applied Geography, 40, pp. 83-89. (2013).

7. H. Holttinen, Hourly wind power variations in the Nordic countries. Wind Energy, 8, pp. 173-195. (2005).

8. I. Žiger, M. Božičević-Vrhovčak, Z. Šimić, Geographical Distribution of Wind Power Plants and Its Influence on Power System Availability Case Study Croatia. Energy Sources, Part A: Recovery, Utilization, and Environmental Effects, 37(8), pp. 854-860. (2015).

9. M.R. Milligan, T. Factor, Optimizing the Geographic Distribution of Wind Plants in Iowa for Maximum Economic Benefit and Reliability. Wind Engineering, 24(4), pp. 271-290. (2000).

10. A. Muzhikyan, A.M. Farid, T. Mezher, The impact of wind power geographical smoothing on operating reserve requirements. American Control Conference (ACC) / Boston, MA, pp. 5891-5896. (2016).

11. D.N. Karamov, Formation of Initial Meteorological Arrays Using Long-term Series FM 12 Synop and METAR in System Energy Studies. Bulletin of the Tomsk Polytechnic University - GEO Assets Engineering, 329(1), pp. 69-88. (2018).

12. D. Karamov, S. Perzhabinsky. The method of processing of initial climatic data for systems energy studies with renewable energy sources. E3S Web Conference, 69, 02014. (2018).

13. V. Shakirov, Methodical approach to the estimation of possible energy production by wind and solar power plants using weather station data. E3S Web Conference, 77, 02008. (2019).

14. E.V. Noskova. Assessment of Wind Energypotential at the Tranbaikal Territory. Transbaikal State University Bulletin, 122(7) pp. 12-19. (2015). (in Russian). 